ORIGINAL ARTICLE

\title{
Work related symptoms among sewage workers: a nationwide survey in Sweden
}

\author{
J Thorn, L Beijer, R Rylander
}

Occup Environ Med 2002;59:562-566

See end of article for authors' affiliations

.....................

Correspondence to: Dr J Thorn, Department of Environmental Medicine, Göteborg University, Box 414, 40530 Gothenburg, Sweden;

jorgen.thorn@envmed.gu.se

Accepted

13 February 2002

\begin{abstract}
Aims: To assess the risk for work related symptoms among sewage workers in Sweden using a postal questionnaire.

Methods: All municipalities in Sweden were contacted and asked to provide addresses of sewage workers and controls. Controls were recruited among other municipal workers not exposed to sewage, such as workers in drinking water plants and gardeners. A questionnaire was sent to the subjects and after two reminders, the response rate was $74 \%$ among sewage workers and $59 \%$ among controls.

Results: Significantly increased risks for airway symptoms, chronic bronchitis, and toxic pneumonitis, as well as central nervous system symptoms such as headache, unusual tiredness, and concentration difficulties were found among the sewage workers compared with controls. Furthermore, an increased risk for non-specific work related gastrointestinal symptoms was found among the sewage workers; an increased risk for joint pains, related to pains in more than four joints but not with loading, was also found.

Conclusions: The results of this questionnaire survey show an increased risk for airway, gastrointestinal, and general symptoms such as joint pains and central nervous system symptoms among sewage workers. Clinical investigations are needed to determine the cause of the reported symptoms among sewage workers, and further field studies are required to assess the causal agents.
\end{abstract}

$\mathrm{O}$ ver the years, there have been several reports of work related symptoms among employees at sewage treatment plants. They have been summarised in two recent reviews. ${ }^{12}$ Symptoms of eye and nose irritation, lower airway symptoms, fever, fatigue, skin symptoms, headache, dizziness, and flu like symptoms were more common among sewage workers. ${ }^{3-10}$ Flu like symptoms with fever, shivering, and headache have been reported among sewage workers handling sludge. ${ }^{11}$ An increased risk/prevalence for asthma and chronic bronchitis among sewage workers, ${ }^{78}$ as well as decreased lung function values have been reported. ${ }^{6712}$ Several studies have reported an increased prevalence of symptoms in the gastrointestinal tract. ${ }^{3591314}$ There are studies reporting an increased prevalence of antibodies against hepatitis $\mathrm{A}^{3}{ }^{15-18}$ and leptospirosis has been reported among sewage workers. ${ }^{19}$ Some studies have suggested a risk of illnesses caused by parasites, for example, Entamoeba histolytica and Giardia lamblia, among sewage workers. ${ }^{30}$

Most previous studies on symptoms among sewage workers were relatively small and they have usually focused on one or a few symptom locations. The purpose of this study was to assess the risk for a broad range of work related symptoms among sewage workers in the whole of Sweden, using a postal questionnaire.

The Ethics Committee of the Faculty of Medicine in Göteborg approved the study.

\section{MATERIALS AND METHODS}

All 289 municipalities in Sweden were contacted and asked to supply home addresses of sewage workers and controls. Controls were recruited among other municipal workers not exposed to sewage, such as workers in drinking water plants and gardeners. A total of 257 of the municipalities delivered addresses of sewage workers $(\mathrm{n}=1953)$ and 211 delivered addresses of controls $(n=1425)$. All subjects received a mailed questionnaire. All questionnaires were checked at arrival, and when incomplete answers were given, the respondents were phoned and asked to give complete answers. After two reminders, the response rate was $74 \%$ among sewage workers $(\mathrm{n}=1453)$ and 59\% among controls $(\mathrm{n}=839)$. When checking the questionnaires, several subjects recruited as controls were found to be partly exposed to sewage. In the analyses, they were classified as partly exposed $(n=332)$. Among the sewage workers, 59 subjects were not exposed to sewage. They were excluded in the analyses.

\section{Questionnaire}

The questionnaire was based on a standard questionnaire developed in a European Union project on investigation of persons handling waste (www.miljomedicin.gu.se). It contained a series of items on the working environment, the length of employment at the present work site, and the type of work carried out, as well as existing diseases. These were followed by a series of questions on different symptoms and diseases present during the most recent 12 months and whether they were work related. Questions were posed on airway and gastrointestinal symptoms, joint pains, and central nervous system symptoms, including headache, unusual tiredness, and concentration difficulties. Special questions related to physician diagnosed allergy, eczema, and asthma. Finally, the questionnaire contained items on smoking habits and alcohol use. Chronic bronchitis was defined as cough with sputum for at least three months a year for a period of at least two years. The question "Have you had episodes of flu like symptoms such as fever, chills, malaise, muscle or joint pain, and perhaps also cough, breathlessness, and weakness, and felt completely well the following day?" was also posed. A positive response was defined as toxic pneumonitis. ${ }^{21}$

\section{Statistical analyses}

The differences between sewage workers (exposed), subjects partly exposed (partly exposed), and controls were analysed using Student's $t$ test and non-parametric tests $\left(\chi^{2}\right.$, Fisher's exact test). 
Table 1 Characteristics of the study population

\begin{tabular}{|c|c|c|c|}
\hline & Controls & Partly exposed & Exposed \\
\hline $\mathrm{n}$ & 507 & 332 & 1394 \\
\hline Smokers (\%) & 17 & 15 & 16 \\
\hline Ex-smokers $(\%)$ & 43 & 43 & 42 \\
\hline Never-smokers (\%) & 40 & 42 & 42 \\
\hline $\begin{array}{l}\text { Using alcohol almost every day/several times per } \\
\text { week (\%) }\end{array}$ & 11 & 9 & 13 \\
\hline Male $(\%)$ & 92 & $96 *$ & $95^{*}$ \\
\hline Age (year) & 49 & 49 & 48 \\
\hline \multicolumn{4}{|l|}{ Physician diagnosed } \\
\hline Asthma (\%) & 6 & 9 & 5 \\
\hline Allergy $(\%)$ & 16 & 13 & 15 \\
\hline Eczema $(\%)$ & 13 & 10 & 12 \\
\hline Working shift (\%) & 7 & 4 * & $16 * * *$ \\
\hline Working full time (\%) & 99 & 100 & 99 \\
\hline Working indoors (hours/day) & 4.4 & 4.1 & $5.4^{* * *}$ \\
\hline Working outdoors (hours/day) & 5.0 & $5.4^{*}$ & $3.2 * * *$ \\
\hline Eating, drinking during work shift (\%) & 47 & 51 & $30 * * *$ \\
\hline Washing hands before meals during work shift (\%) & 98 & 99 & $100 * *$ \\
\hline Having a shower after work (\%) & 63 & 67 & $90 * * *$ \\
\hline Changing clothes after work (\%) & 72 & 81 ** & $92 * * *$ \\
\hline Cleaning duties at the work place (\%) & 29 & $47 * * *$ & $72 * * *$ \\
\hline Chemical use at the work place (\%) & 65 & 66 & $80 * * *$ \\
\hline Using protective equipment (\%) & 63 & $86 * * *$ & $90 * * *$ \\
\hline Dust exposure (days/month) & 3.2 & 5.4 ** & $6.3 * * *$ \\
\hline Monotonous work (\%) & 13.7 & 9.8 & $7.9 * * *$ \\
\hline
\end{tabular}

Logistic regression analyses were performed to compute adjusted odds ratios (OR) with $95 \%$ confidence intervals (CI) while controlling for age, gender, and smoking habits (neversmoker/ever-smoker). As several sewage workers also worked in drinking water plants, which also use chemicals, it is theoretically possible that this workplace exposure could influence the results. Separate analyses controlling also for work in drinking water plants were therefore performed. To analyse the prevalence of symptoms at different work stations, a stepwise multivariate logistic regression model was applied, with adjustments for age, gender, smoking habits (never-smoker/ ever-smoker), and interactions between different work stations. Another stepwise multivariate logistic regression model, with adjustments for age, gender, and smoking habits (neversmoker/ever-smoker), was applied to adjust for interactions between different symptoms.

\section{RESULTS}

Table 1 shows the characteristics of the study population. There was a larger proportion of males in the exposed groups compared with controls. There were no differences in smoking habits, alcohol use, full time employment, and physician diagnosed asthma or allergy between the exposed and controls. Among the exposed, a larger proportion worked shift/indoors, had a shower and changed clothes after work shift, had cleaning duties, used protective equipment, and reported chemical use and dust exposure at work compared with controls.

Analyses of working characteristics in relation to years of employment as a sewage worker showed that the proportion of workers who reported eating, drinking during work shift, and having a shower after work was higher with an increasing number of years of employment in a time-response fashion (data not shown).

Table 2 Proportions of self reported airway symptoms among the exposed, partly exposed, and controls; adjusted odds ratios (OR) with $95 \%$ confidence intervals (CI) are presented, controlling for age, gender, smoking habits, and work in drinking water plants

\begin{tabular}{|c|c|c|c|c|c|c|}
\hline \multirow[b]{2}{*}{ Airway symptoms } & \multicolumn{2}{|c|}{ Controls } & \multicolumn{2}{|c|}{ Partly exposed } & \multicolumn{2}{|c|}{ Exposed } \\
\hline & $\%$ & OR & $\%$ & OR $(95 \% \mathrm{Cl})$ & $\%$ & OR $(95 \% \mathrm{Cl})$ \\
\hline \multicolumn{7}{|l|}{ Present during the most recent 12 months } \\
\hline Breathlessness when exposed to gases, fumes, smells & 12.6 & 1 & 19.8 & $1.8(1.2$ to 2.7$)$ & 25.3 & 2.4 (1.8 to 3.2$)$ \\
\hline Breathlessness during exercise & 18.5 & 1 & 20.1 & $1.1(0.8$ to 1.6$)$ & 25.9 & $1.6(1.2$ to 2.0$)$ \\
\hline Chest tightness during work shift & 8.3 & 1 & 13.3 & $1.7(1.1$ to 2.7$)$ & 12.4 & $1.5(1.1$ to 2.2$)$ \\
\hline Chronic bronchitis & 4.2 & 1 & 8.0 & $2.1(1.2$ to 3.9$)$ & 10.9 & $2.8(1.7$ to 4.5$)$ \\
\hline Toxic pneumonitis & 4.2 & 1 & 8.2 & $2.2(1.2$ to 4.0$)$ & 19.3 & $5.4(3.4$ to 8.5$)$ \\
\hline Breathlessness when walking up stairs & 13.6 & 1 & 16.0 & $1.3(0.9$ to 1.9$)$ & 21.9 & $1.8(1.4$ to 2.5$)$ \\
\hline Breathlessness when walking on plain ground & 3.2 & 1 & 3.9 & $1.5(0.7$ to 3.2$)$ & 6.3 & 2.2 (1.3 to 3.9$)$ \\
\hline $\begin{array}{l}\text { Breathlessness when walking with other persons of } \\
\text { similar age }\end{array}$ & 4.2 & 1 & 6.6 & $1.9(1.0$ to 3.5$)$ & 9.3 & $2.6(1.6$ to 4.2$)$ \\
\hline Wheezing chest without having a cold & 9.5 & 1 & 10.0 & $1.1(0.7$ to 1.8$)$ & 14.7 & $1.7(1.2$ to 2.4$)$ \\
\hline Breathlessness during cold weather & 7.4 & 1 & 8.1 & $1.1(0.7$ to 1.9$)$ & 10.0 & $1.4(1.0$ to 2.1$)$ \\
\hline \multicolumn{7}{|l|}{ Symptoms reported daily/1-2 times per week } \\
\hline Throat irritation & 4.3 & 1 & 6.1 & $1.5(0.8$ to 3.0$)$ & 10.3 & $2.8(1.7$ to 4.5$)$ \\
\hline Nose irritation & 14.6 & 1 & 13.4 & $0.9(0.6$ to 1.4$)$ & 23.3 & 1.8 (1.4 to 2.5$)$ \\
\hline Congested nose & 10.4 & 1 & 11.7 & $1.1(0.7$ to 1.8$)$ & 19.5 & $2.1(1.5$ to 2.9$)$ \\
\hline Cough with phlegm & 7.8 & 1 & 11.5 & $1.6(1.0$ to 2.6$)$ & 14.2 & $2.0(1.4$ to 2.9$)$ \\
\hline Dry cough & 5.3 & 1 & 8.3 & $1.7(1.0$ to 3.1$)$ & 12.6 & $2.8(1.8$ to 4.3$)$ \\
\hline
\end{tabular}


Table 3 Proportions of self reported gastrointestinal symptoms and joint pains among the exposed, partly exposed, and controls; adjusted odds ratios (OR) with $95 \%$ confidence intervals (CI) are presented, controlling for age, gender, smoking habits, and work in drinking water plants

\begin{tabular}{|c|c|c|c|c|c|c|}
\hline \multirow[b]{2}{*}{ Symptoms } & \multicolumn{2}{|c|}{ Controls } & \multicolumn{2}{|c|}{ Partly exposed } & \multicolumn{2}{|c|}{ Exposed } \\
\hline & $\%$ & OR & $\%$ & OR $(95 \% \mathrm{Cl})$ & $\%$ & OR $(95 \% \mathrm{Cl})$ \\
\hline \multicolumn{7}{|l|}{ Present during the most recent 12 months } \\
\hline Soft stools & 38.8 & 1 & 45.4 & $1.3(1.0$ to 1.7$)$ & 60.6 & $2.5(2.0$ to 3.1$)$ \\
\hline Soft stools related to work & 2.4 & 1 & 7.7 & $3.4(1.7$ to 6.8$)$ & 27.5 & $15.4(8.6$ to 27.8$)$ \\
\hline Diarrhoea & 13.0 & 1 & 15.4 & $1.2(0.8$ to 1.8$)$ & 23.9 & $2.1(1.6$ to 2.9$)$ \\
\hline Diarrhoea related to work & 1.4 & 1 & 3.7 & $2.6(1.0$ to 6.7$)$ & 13.3 & $10.9(5.1$ to 23.4$)$ \\
\hline $\begin{array}{l}\text { Other family members suffered from } \\
\text { diarrhoea at the same time }\end{array}$ & 28.3 & 1 & 18.6 & $0.7(0.3$ to 1.5$)$ & 10.0 & $0.3(0.2$ to 0.5$)$ \\
\hline Stomach pain & 24.5 & 1 & 32.8 & $1.5(1.1$ to 2.1$)$ & 38.4 & $2.0(1.6$ to 2.5$)$ \\
\hline Joint pains & 33.8 & 1 & 40.3 & $1.4(1.0$ to 1.8$)$ & 42.7 & $1.5(1.2$ to 1.9$)$ \\
\hline Joint pains in relation to loading & 64.0 & 1 & 62.9 & $0.9(0.5$ to 1.4$)$ & 54.0 & $0.6(0.4$ to 0.9$)$ \\
\hline Pains in $>4$ joints & 22.2 & 1 & 26.9 & $1.5(0.9$ to 2.7$)$ & 32.4 & $1.7(1.1$ to 2.6$)$ \\
\hline Wrist pains & 46.9 & 1 & 51.0 & $1.3(0.8$ to 2.3$)$ & 60.5 & $2.0(1.3$ to 3.0$)$ \\
\hline \multicolumn{7}{|c|}{ Symptoms reported daily/1-2 times per week } \\
\hline Nausea & 0.6 & 1 & 1.9 & $3.5(0.8$ to 14.3$)$ & 4.7 & 8.5 (2.7 to 27.4$)$ \\
\hline
\end{tabular}

Table 4 Proportions of self reported central nervous system (CNS) symptoms among the exposed, partly exposed, and controls; adjusted odds ratios (OR) with $95 \%$ confidence intervals (CI) are presented, controlling for age, gender, smoking habits, and work in drinking water plants

\begin{tabular}{|c|c|c|c|c|c|c|}
\hline \multirow[b]{2}{*}{ CNS symptoms } & \multicolumn{2}{|c|}{ Controls } & \multicolumn{2}{|c|}{ Partly exposed } & \multicolumn{2}{|c|}{ Exposed } \\
\hline & $\%$ & OR & $\%$ & OR $(95 \% \mathrm{CI})$ & $\%$ & OR $(95 \% \mathrm{Cl})$ \\
\hline \multicolumn{7}{|c|}{ Symptoms reported daily/1-2 times per week } \\
\hline Headache & 8.1 & 1 & 8.3 & $1.1(0.6$ to 1.8$)$ & 14.9 & 2.0 (1.4 to 2.9$)$ \\
\hline Muscle pains (not due to exercise) & 10.7 & 1 & 13.0 & $1.3(0.8$ to 2.1$)$ & 15.3 & $1.6(1.1$ to 2.2$)$ \\
\hline Concentration difficulties & 4.9 & 1 & 5.9 & $1.3(0.7$ to 2.4$)$ & 12.5 & $3.1(1.6$ to 5.9$)$ \\
\hline Eye irritation & 8.6 & 1 & 9.0 & $1.1(0.7$ to 1.9$)$ & 12.8 & $1.6(1.1$ to 2.2$)$ \\
\hline Unusual tiredness & 9.4 & 1 & 14.9 & $1.7(1.1$ to 2.7$)$ & 32.5 & $4.9(3.5$ to 6.8$)$ \\
\hline Heaviness in the head & 4.5 & 1 & 5.8 & $1.3(0.7$ to 2.6$)$ & 16.6 & $4.2(2.7$ to 6.7$)$ \\
\hline
\end{tabular}

Table 2 shows the proportions and adjusted OR with 95\% CI for self reported airway symptoms among the exposed, partly exposed, and controls. Among the exposed, an increased risk for upper and lower airway effects such as nose irritation, congested nose, cough, breathlessness in different situations, wheezing, chest tightness during work shift, chronic bronchitis, and toxic pneumonitis was found compared with controls.

Among the partly exposed, an increased risk for airway effects such as breathlessness when exposed to gases etc, chest tightness during work shift, chronic bronchitis, and toxic pneumonitis was found compared with controls.

Table 3 shows the proportions and adjusted OR with 95\% CI for self reported gastrointestinal symptoms and joint pains among the exposed, partly exposed, and controls. Among the exposed, an increased risk for soft stools/diarrhoea related to work, nausea, and stomach pain was found. There was a decreased risk that other family members suffered from diarrhoea at the same time. An increased risk for joint pains was found among the exposed compared with controls, and the joint pains were related to pains in more than four joints but not with loading. Among the partly exposed, an increased risk for soft stools related to work and stomach pain was found compared with controls.

Table 4 shows the proportions and adjusted OR with 95\% CI for self reported central nervous system symptoms among the exposed, partly exposed, and controls. Among the exposed, an increased risk for headache, concentration difficulties, unusual tiredness, and heaviness in the head was found compared with controls. Among the partly exposed, an increased risk for unusual tiredness was found.

Table 5 shows a multivariate logistic regression analysis, controlling for age, gender, and smoking habits, for interac-
Table 5 Multivariate logistic regression analysis for interactions between different symptoms among the exposed in relation to controls; adjusted odds ratios (OR) with $95 \%$ confidence intervals (CI) are presented (controlling for age, gender, and smoking habits) for the significant symptoms

\begin{tabular}{ll}
\hline Symptoms & OR $(95 \% \mathrm{Cl})$ \\
\hline Toxic pneumonitis & $3.2(1.8$ to 5.6$)$ \\
Unusual tiredness & $3.1(2.0$ to 5.0$)$ \\
Breathlessness when walking with other & $2.4(1.1$ to 5.2$)$ \\
persons of similar age & $1.8(1.1$ to 2.7$)$ \\
Congested nose & $9.4(4.9$ to 18.2$)$ \\
Soft stools related to work & \\
\hline
\end{tabular}

tions between different symptoms among the exposed in relation to controls. In this model, an increased risk for toxic pneumonitis, unusual tiredness, congested nose, and soft stools related to work was found among the exposed.

Table 6 shows a multivariate logistic regression analysis of reported symptoms in relation to work at different work stations. Adjusted OR with 95\% CI are presented, controlling for age, gender, smoking habits, and interactions between work at different work stations.

Some of the above reported symptoms were increased in relation to work at pump stations or filter units or sludge handling. Work at covered basins was not associated with an increased risk for any symptoms. 
Table 6 Multivariate logistic regression analysis of the most extensive symptoms in relation to work at different work stations; adjusted OR with $95 \% \mathrm{Cl}$ are presented, controlling for age, gender, smoking habits, and interactions between work at different work stations

\begin{tabular}{ll}
\hline Symptoms & OR (95\% CI) \\
\hline $\begin{array}{l}\text { Pump stations } \\
\text { Breathlessness when exposed to gases etc }\end{array}$ & $1.4(1.1$ to 1.9$)$ \\
Soft stools related to work & $1.4(1.0$ to 1.8$)$ \\
Throat irritation & $1.6(1.05$ to 2.4$)$ \\
Unusual tiredness & $1.4(1.05$ to 1.8$)$ \\
Filter units & $1.8(1.2$ to 2.6$)$ \\
Soft stools related to work & $2.5(1.4$ to 4.2$)$ \\
Diarrhoea related to work & $1.9(1.3$ to 2.7$)$ \\
Nose irritation & $1.8(1.1$ to 2.9$)$ \\
Cough with phlegm & $1.4(1.0$ to 1.9$)$ \\
Unusual tiredness & $1.8(1.1$ to 2.9$)$ \\
Concentration difficulties & $2.0(1.1$ to 3.7$)$ \\
Sludge handling & $2.3(1.3$ to 3.9$)$ \\
Toxic pneumonitis & $2.0(1.2$ to 3.2$)$ \\
Soft stools related to work & $1.0(0.7$ to 1.3$)$ \\
Unusual tiredness & $1.1(0.8$ to 1.5$)$ \\
Covered basins & $0.5(0.3$ to 0.8$)$ \\
Breathlessness when exposed to gases etc & \\
Toxic pneumonitis & $1.0(0.6$ to 1.5$)$ \\
Breathlessness when walking on plain & $1.0(0.8$ to 1.4$)$ \\
ground & $1.1(0.8$ to 1.6$)$ \\
Throat irritation & $0.8(0.6$ to 1.1$)$ \\
Nose irritation & $1.0(0.7$ to 1.4$)$ \\
Cough with phlegm & $0.8(0.6$ to 1.0$)$ \\
Unusual tiredness & $0.8(0.6$ to 1.1$)$ \\
Concentration difficulties & $0.7(0.5$ to 0.99$)$ \\
Soft stools & \\
Soft stools related to work & \\
Diarrhoea related to work & \\
\hline &
\end{tabular}

\section{DISCUSSION}

The controls were recruited among other municipal personnel not exposed to sewage and with similar socioeconomic status as the sewage workers. The response rate was lower among controls compared with sewage workers. This is often a practical reality, as the working environment of the controls was not investigated. However, the prevalence of different symptoms among the controls was similar compared with other similar control groups in previous studies. ${ }^{7-9} 131422$ The results were based on self reporting of certain symptoms and diseases, working environments, and exposures by a mailed questionnaire. The sewage workers may be more prone to report their symptoms, especially if the symptoms have been discussed in association with working with sewage. Thus, there is a possibility that over reporting to some extent can be responsible for the differences found between the exposed and controls.

A significantly increased risk for several airway symptoms, chronic bronchitis, and toxic pneumonitis was found among the sewage workers compared with controls. Several previous studies have shown that airway symptoms are more common among sewage workers than in controls. ${ }^{3-10}$ An increase in airway symptoms has also been reported in earlier investigations on workers in organic dust environments in general. ${ }^{21}$ An increased prevalence of toxic pneumonitis is a common finding in investigations of organic dust environments and has been related to endotoxin exposure. ${ }^{21}$ In sewage workers handling sludge, similar reactions with flu like symptoms have previously been described. ${ }^{4}{ }^{6}$ In such workers, flu like symptoms have also been related to Legionella pneumophila infection. ${ }^{11}$ Furthermore, an increased risk/prevalence of asthma and chronic bronchitis has been reported among sewage workers, ${ }^{78}$ as well as decreased lung function values. ${ }^{67} 12$

\section{Main messages}

- The results of this questionnaire survey on sewage workers in Sweden show an increased risk for:

- upper and lower airway symptoms

- non-specific gastrointestinal symptoms

- general symptoms, such as joint pains and central nervous system symptoms.

- The risk for certain symptoms is related to certain work sites.

- Further investigations are needed to determine the cause of the reported symptoms among sewage workers, and to assess causal agents.

\section{Policy implications}

- Reports of airway, non-specific gastrointestinal, and general symptoms should be taken to indicate unhealthy work conditions in sewage handling.

- Results indicate the need for further investigations to determine the cause of the reported symptoms among sewage workers and to assess the causal agents.

An increased risk for non-specific gastrointestinal symptoms was found among the sewage workers. Work related lower gastrointestinal symptoms were the most common. There was a decreased risk for other family members to suffer from diarrhoea at the same time, indicating that the symptoms were related to the work and not to a family derived infection. Several previous studies have shown that gastrointestinal symptoms are more common among sewage workers than in controls. ${ }^{351314}$ The symptoms reported from the gastrointestinal tract are not diagnostic of specific diseases such as stomach ulcer or ulcerative colitis.

An increased risk for central nervous system symptoms such as headache, heaviness in the head, unusual tiredness, and concentration difficulties was found among the sewage workers. Similar findings have been reported previously. ${ }^{5}{ }^{23}{ }^{24}$ An increased prevalence of unusual tiredness is frequently reported in studies investigating workers/persons in organic dust environments. ${ }^{21}{ }^{25}$ An increased risk for joint pains was found among the sewage workers, and similar results have been reported previously. ${ }^{9}$ In this study, the joint pains were related to pains in more than four joints but not with loading, indicating an inflammatory/systemic response among the sewage workers. However, this must be further investigated in future studies, including clinical markers of inflammation.

Analyses controlling for interactions between different work stations at sewage treatment plants, indicated that work at covered basins is not associated with an increased risk for symptoms. This finding can be the result of a different exposure situation at these work stations, including less aerosolisation of the sewage water.

Regarding possible causative agents for the symptoms observed, viruses such as Norwalk agent, other microorganisms, or endotoxin have been suggested. ${ }^{39}{ }^{10}$ Of the different components in microorganisms, bacterial endotoxins are of particular interest. They can be present in sewage treatment plants in amounts that exceed those that give rise to symptoms and illness. ${ }^{921}$ The acute effects of endotoxins are well documented in several inhalation experiments in man. ${ }^{26-30}$ Relations between symptoms such as those found in this study (for example, airway symptoms, toxic pneumonitis, and unusual tiredness) and endotoxin exposure in different environments have previously been reported. ${ }^{2}$

In conclusion, the results of this questionnaire survey show an increased risk for airway, gastrointestinal, and general symptoms such as joint pains and central nervous system 
symptoms among sewage workers. Clinical investigations are needed to determine the cause of the reported symptoms among sewage workers, and further field studies are required to assess the causal agents.

\section{ACKNOWLEDGEMENTS}

The study was supported by the Swedish Council for Work Life Research (1999-0397), the Unions of Municipality Workers, The Swedish Association of Local Authorities, and the Water and Sewage Association, Sweden.

\section{Authors' affiliations}

J Thorn, L Beijer, R Rylander, Department of Environmental Medicine, Göteborg University, Sweden

\section{REFERENCES}

1 Thorn J, Kerekes E. Health effects among employees in sewage treatment plants: a literature survey. Am J Ind Med 2001:40:170-9.

2 Mulloy KB. Sewage workers: toxic hazards and health effects. Occup Med 2001; 16:23-38

3 Clark SC. Potential and actual biological related health risks of wastewater industry employment. J Water Pollut Contr Fed 1987:59:999-1008

4 Mattsby I, Rylander R. Clinical and immunological findings in workers exposed to sewage dust. J Occup Med 1978;20:690-2.

5 Scarlett-Kranz JM, Babish JG, Srickland D, et al. Health among municipal sewage and water treatment workers. Toxicol Ind Health 1987:3:311-19.

6 Nethercott JR, Holness DL. Health status of a group of sewage treatment workers in Toronto, Canada. Am Ind Hyg Assoc J 1988;49:346-50.

7 Zuskin E, Mustafbegovic J, Schacter EN. Respiratory function in sewage workers. Am J Ind Med 1993;23:751-61.

8 Friis L, Norbäck D, Edling C. Self-reported asthma and respiratory symptoms in sewage workers. J Occup Health 1999;41:87-90.

9 Rylander R. Health effects among workers in sewage treatment plants. $J$ Occup Env Med 1999;56:354-7.

10 Melbostadt E, Eduard W, Skogstad A, et al. Exposure to bacterial aerosols and work-related symptoms in sewage workers. Am J Ind Med 1994;25:59-63

11 Gregersen P, Grunnet K, Uldum SA, et al. Pontiac fever at a sewage treatment plant in the food industry. Scand J Work Environ Health 1999;25:291-5.
12 Richardson DB. Respiratory effects of chronic hydrogen sulfide exposure. Am J Ind Med 1995;28:99-108.

13 Lundholm $M$, Rylander R. Work-related symptoms among sewage workers. Br J Ind Med 1983:40:325-9.

14 Friis L, Agréus L, Edling C. Abdominal symptoms among sewage workers. Occup Med 1998;48:251-3.

15 Skinhoj P, Blain Hollinger F, Hovind-Hougen K, et al. Infectious liver diseases in three groups of Copenhagen workers: correlation of hepatitis A infection to sewage exposure. Arch Environ Health 1981;36:139-43.

16 Shakespeare A, Poole J. Sewage workers and hepatitis A. Occup Health 1993;45:364-6.

17 Heng BH, Goh KT, Doraisingham S, et al. Prevalence of hepatitis A virus infection among sewage workers in Singapore. Epidemiol Infect 1994; 113:121-8.

18 Brugha R, Heptonstall J, Farrington P, et al. Risk of hepatitis A infection in sewage workers. Occup Environ Med 1998:55:567-9.

19 De Serres G, Levesque B, Higgins R, et al. Need for vaccination of sewer workers against leptospirosis and hepatitis A. Occup Environ Med 1995;52:505-7.

20 Heap BJ, McCulloch ML. Giardiasis and occupational risk in sewage workers. Lancet 1991;338:1404-5.

21 Rylander R. Endotoxins in the environment-a criteria document. Int J Occup Environ Health 1997;3:S1-48

22 Khuder SA, Arthur T, Bisesi MS, et al. Prevalence of infectious diseases and associated symptoms in wastewater treatment workers. Am J Ind Med 1998;33:571-7.

23 Dean RB. Assessment of disease rates among sewer workers in Copenhagen, Denmark. Environmental Health Effects Research Series, EPA-600/1-78-007, 1978:1-11.

24 Kraut A, Lilis R, Marcus $M$, et al. Neurotoxic effects of solvent exposure on sewage treatment workers. Arch Environ Health 1988;43:263-8.

25 Rylander R, Thorn J, Attefors R. Airways inflammation among workers in a paper industry. Eur Respir J 1999;13:1151-7.

26 Rylander R, Bake B, Fisher JJ, et al. Pulmonary function and symptoms after inhalation of endotoxin. Am Rev Respir Dis 1989;140:981-6.

27 Herbert A, Carvalheiro MF, Rubenowitz E, et al. Reduction of alveolar-capillary diffusion after inhalation of endotoxin in normal subiects. Chest 1992;102:1095-8.

28 Michel O, Duchateau J, Plat G, et al. Blood inflammatory response to inhaled endotoxin in normal subjects. Clin Exp Allergy 1995;25:73-9.

29 Michel O, Nagy AM, Schroeven M, et al. Dose-response relationship to inhaled endotoxin in normal subjects. Am J Respir Crit Care Med 1997; 156: 1 157-64.

30 Thorn J, Rylander R. Inflammatory response after inhalation of bacterial endotoxin assessed by the induced sputum technique. Thorax 1998;53:1047-52

\section{$\mathrm{ECHO}$}

Working to reduce work disability in rheumatoid arthritis

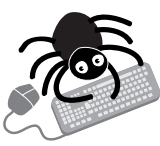

Please visit the Occupational and

Environmental Medicine website [www. occenvmed] for link to this full article. study of patients with rheumatoid arthritis (RA) may point the way towards better treatment,

$\triangle$ thereby allowing them to stay in work longer. By identifying predictors of loss of paid work early in the course of the disease the study paves the way for management programmes better suited to facilitating coping at work - with alternatives to using drugs to control the condition-before work disability sets in.

Forty per cent of the 353 recruits working at entry to the study were not working five years later, over half $(56 \%)$ because of RA. Work disability was more likely with manual work (odds ratio $2.97,95 \%$ confidence interval 1.26 to 6.9$)$, joint erosions $(2.09,1.19$ to 3.64$)$, high erythrocyte sedimentation rate (ESR) (2.37, 1.4 to 3.9), and worse baseline scores for the disability index of the Health Assessment Questionnaire (HAQ $\geqslant 1.5 ; 2.26,1.38$ to 3.7). With HAQ score, ESR, age of onset of RA, joint erosions, and sex, work outcome was predicted in $78 \%$ in multivariate analysis.

The findings are from a five year follow up of 723 patients in the early RA study (ERAS). The patients were consecutive attendees at rheumatology clinics in nine districts in England whose onset of RA was no more than two years previously and who had not started second line treatment. They were assessed yearly for a range of clinical variables-pain/swelling, erosions, disability index, ESR, rheumatoid factor-other illnesses; socioeconomic indicators; and type of employment, including change in working hours, sick leave, and permanent work disability.

A Annals of the Rheumatic Diseases 2002:61:335-340. 